\title{
SITUAÇÕES DE JOGO CAUSADORAS DE ESTRESSE EM ATLETAS DAS CATEGORIAS DE BASE DE HANDEBOL: UMA ABORDAGEM CROSS-CULTURAL
}

Daniel Alvarez Pires

Lucinar Jupir Forner Flores

Maria Regina Ferreira Brandão

\section{Resumo}

Esse estudo objetivou identificar as situações de jogo causadoras de estresse em atletas das categorias de base do handebol e compará-las entre duas regiões: Oeste do Paraná e Campinas (SP). Participaram da pesquisa 53 atletas de ambos os sexos, com idades entre 13 e 21 anos. Foi utilizado o "Situações de Stress no Handebol" (SSH), além de uma pergunta aberta. Foram calculadas a freqüência e porcentagem de respostas "sim" dadas a cada um dos itens do SSH. Quanto à pergunta aberta, as situações de jogo encontradas foram agrupadas em categorias de respostas denominadas fontes de estresse. Percebeu-se que, dos cinco principais itens considerados estressantes por cada um dos grupos, quatro foram comuns a ambos. Apesar da distância que separa as regiões, ocorreram semelhanças na percepção das situações estressantes durante o jogo.

\section{Palavras-Chave}

Handebol; Estresse; Situações de Jogo.

\section{SITUATIONS OF THE GAME CAUSE OF STRESS IN ATHLETES OF THE CATEGORIES OF HANDEBALL BASE: A CROSS-CULTURAL APPROACH}

Daniel Alvarez Pires

Lucinar Jupir Forner Flores

Maria Regina Ferreira Brandão

\begin{abstract}
This study aimed to identify the game situations that cause stress in young handball athletes and compare them into two regions: West Paraná and Campinas (SP). The participants were 53 athletes (men and women), with ages ranging from 13 to 21 years. The "Situações de Stress no Handebol" (SSH) instrument was used with an open question. The frequency and percentage of "yes" answers given in each item of the SSH were calculated. About the open question, the game situations informed were grouped in answers categories named sources of stress. Trough the five main game situations perceived as stressing by each group, four were the same for both. Despite the distance between the two regions, there were observed similarities in the perception of stressing situations during the game.
\end{abstract}

\section{Key-Words}

Handball; Stress; Game Situations. 


\section{INTRODUÇÃO}

O modelo primitivo da prática de handebol no Brasil surgiu por volta de 1930, com a implantação do "handebol de campo" por imigrantes israelitas e alemães. Mesmo sem a presença de registros concretos e bem detalhados, sugere-se que o handebol de quadra passou a existir no país no início da década de 1950, extinguindo-se, assim, o handebol de campo (ZAMBERLAN, 1999b).

De acordo com relatos históricos, o Estado de São Paulo manteve a hegemonia nacional no esporte até o ano de 1973, quando, então, começou e receber a companhia de Estados como Minas Gerais, Paraná e Rio Grande do Sul (ZAMBERLAN, 1999b). Atualmente, esse panorama não apresenta transformações significativas em relação a três décadas atrás. Segundo Alberto Rigolo, técnico da Seleção Brasileira Adulta Masculina nas Olimpíadas de Atenas-2004 e ex-técnico da Equipe da Metodista São Bernardo do Campo-SP, em palestra não-publicada proferida na Universidade de São Paulo (USP) no ano de 2004, o Estado de São Paulo ainda mantém o maior status no handebol brasileiro, seja na vertente política (estruturação da Federação Estadual, organização de eventos, contatos políticos) ou na vertente técnica (número global de praticantes, número de equipes competitivas, número de títulos nacionais e internacionais de suas equipes). Esses pontos abordados por Rigolo corroboram com os levantamentos da Confederação Brasileira de Handebol (CBHb, 2002). No entanto, já é possível observar hoje a evolução da modalidade no Paraná e Santa Catarina, onde há equipes disputando a Liga Nacional, bem como atletas sendo revelados e compondo as Seleções Nacionais de várias categorias em ambos os naipes, além de exportar jogadores para o continente europeu, onde estão firmadas as maiores equipes do mundo.

Conforme o artigo 29 da seção III do regulamento oficial da Confederação Brasileira de Handebol (CBHB, 2007), a Tabela 1 apresenta as diferentes categorias da modalidade, com suas respectivas faixas etárias e gêneros. 
Tabela 1: Categorias e faixas etárias do handebol no Brasil (CBHB, 2007).

\begin{tabular}{|c|c|c|}
\hline \multirow[b]{2}{*}{ Categoria } & \multicolumn{2}{|c|}{ Faixas Etárias } \\
\hline & Masculino & Feminino \\
\hline Mini & $\begin{array}{c}\text { Até } 10 \text { anos, completados no ano } \\
\text { da competição }\end{array}$ & $\begin{array}{c}\text { Até } 10 \text { anos, completados no ano } \\
\text { da competição }\end{array}$ \\
\hline Mirim & $\begin{array}{c}11 \text { e } 12 \text { anos, completados no ano } \\
\text { da competição }\end{array}$ & $\begin{array}{c}11 \text { e } 12 \text { anos, completados no ano } \\
\text { da competição }\end{array}$ \\
\hline Infantil & $\begin{array}{l}13 \text { e } 14 \text { anos, completados no ano } \\
\text { da competição }\end{array}$ & $\begin{array}{c}13 \text { e } 14 \text { anos, completados no ano } \\
\text { da competição }\end{array}$ \\
\hline Cadete & $\begin{array}{c}15 \text { e } 16 \text { anos, completados no ano } \\
\text { da competição }\end{array}$ & $\begin{array}{c}15 \text { e } 16 \text { anos, completados no ano } \\
\text { da competição }\end{array}$ \\
\hline Juvenil & $\begin{array}{c}17 \text { e } 18 \text { anos, completados no ano } \\
\text { da competição }\end{array}$ & $\begin{array}{c}17 \text { e } 18 \text { anos, completados no ano } \\
\text { da competição }\end{array}$ \\
\hline Júnior & $\begin{array}{c}19 \text { e } 20 \text { anos, completados no ano } \\
\text { da competição }\end{array}$ & $\begin{array}{c}19 \text { e } 20 \text { anos, completados no ano } \\
\text { da competição }\end{array}$ \\
\hline Adulto & $\begin{array}{c}\text { A partir de } 21 \text { anos, completados } \\
\text { no ano da competição }\end{array}$ & $\begin{array}{c}\text { A partir de } 21 \text { anos, completados } \\
\text { no ano da competição }\end{array}$ \\
\hline
\end{tabular}

As variações climáticas, ambientais, econômicas e sociais permitem que, em uma nação de proporções continentais, como o Brasil, sejam percebidas profundas diversidades culturais. No âmbito da Psicologia do Esporte, as diferenças comportamentais entre atletas de regiões distintas têm despertado o interesse de pesquisadores da área. A importância de tal investigação reside no fato de que a ciência tende a refletir os valores e as visões da cultura dominante (RAM, STAREK e JOHNSON, 2004). Portanto, estudos que analisam particularidades como as etnias dos atletas desempenham papel contrário a essa visão dominante no meio da pesquisa científica. Brandão, Casal e González (2001) também defendem a relevância da investigação cross-cultural, ao considerarem-na essencial para a compreensão do atleta.

Dentre as variáveis psicológicas estudadas em atletas, o estresse constitui-se uma das mais abordadas em publicações científicas. Brandão (2000, p. 18) caracteriza o estresse como "um processo psico-biológico complexo que consiste de quatro elementos: a situação estressante; a cognição ou pensamento; a reação emocional; e as conseqüências". Para Samulski (2002), o entendimento do estresse deve levar em consideração a interdependência entre os processos biológicos, psicológicos e sociológicos. Apesar de ser considerado um fenômeno que proporciona conseqüências físicas, mentais e comportamentais exclusivamente negativas, sabe-se hoje que padrões ótimos de estresse são desejáveis na preparação do organismo do atleta visando à boa performance (BRANDÃO, 2000). A autora comenta que o estresse positivo "deixa o indivíduo alerta e estimulado fisiologicamente, ajudando-o a manter o foco de atenção, 
a motivação, o entusiasmo e a conservar um alto nível de energia física" (p. 3). Portanto, torna-se essencial a abordagem bidirecional do estresse, na qual sejam abordados tanto o enfoque negativo (reação denominada distresse) quanto o enfoque positivo (eustresse). Do mesmo modo, é de extrema importância a avaliação da percepção de estresse em atletas de acordo com sua herança cultural, pois as diferenças interculturais apontam para uma diversidade de possibilidades de demandas e enfrentamentos do estresse (BRANDÃO et al., 2001).

No universo esportivo, as exigências estressantes impostas ao atleta podem ser agrupadas em sete grandes fontes de estresse (BRANDÃO, 2000): 1) expectativas sobre o desempenho; 2) fatores pessoais; 3) aspectos da competição; 4) demandas físicas; 5) relacionamentos com pessoas significativas; 6) experiências traumáticas; e 7) variáveis episódicas.

Apesar de estarem amplamente difundidas no esporte em geral e no handebol em particular, as pesquisas sobre estresse pouco contemplam as origens culturais dos atletas. No âmbito das categorias de base, são raros os registros acerca da influência dos aspectos culturais na pressão física e psicológica freqüentemente exercida pelos pais e técnicos em busca de resultados expressivos, enfatizando-se o alto rendimento precoce e, por outro lado, afastando-se do caráter formativo, humanista do esporte.

\section{OBJETIVOS}

Esse estudo tem como objetivos identificar as situações de jogo causadoras de estresse em atletas de handebol pertencentes às categorias de base (infantil, cadete, juvenil e júnior) e compará-las entre duas regiões culturais e geográficas diferentes: a parte Oeste do Estado do Paraná, englobando os municípios de Marechal Cândido Rondon, Cascavel e Santa Helena, e a cidade de Campinas, no Estado de São Paulo.

\section{MATERIAIS E MÉTODOS AMOSTRA}

A Tabela 2 mostra o número de participantes da pesquisa, divididos por região, gênero e categoria.

Tabela 2: Número de participantes da pesquisa, classificados por região, gênero e categoria.

\begin{tabular}{cccccc}
\hline \multicolumn{5}{c}{$\begin{array}{c}\text { Oeste do Paraneros de participantes } \\
\text { Campinas-SP }\end{array}$} & \multicolumn{2}{c}{$\begin{array}{c}\text { Campina } \\
\text { Categoria }\end{array}$} & Masculino & Feminino & Masculino & Feminino & Total \\
\hline Infantil & 05 & 08 & 00 & 01 & 14 \\
Cadete & 08 & 03 & 03 & 06 & 20 \\
Juvenil & 00 & 06 & 03 & 03 & 12 \\
Júnior & 00 & 00 & 05 & 02 & 07 \\
Total & 13 & 17 & 11 & 12 & 53 \\
\hline
\end{tabular}


Participaram do estudo 53 atletas de handebol, sendo 24 homens e 29 mulheres, com idade média de $16,10 \pm 2,02$ anos, pertencentes às categorias infantil, cadete, juvenil e júnior. A idade de iniciação esportiva dos avaliados no handebol variou entre 8 e 16 anos, com média de 12,10 $\pm 1,91$ anos. Vale ressaltar que todos possuíam pelo menos 2 anos de participações em equipes com treinamentos periódicos, além de competições, convocações e demais eventos com este caráter. A amostra foi dividida em 2 grupos: Oeste do Paraná, composto por 30 atletas, abrangendo esportistas dos municípios de Cascavel, Marechal Cândido Rondon e Santa Helena; e Campinas-SP, composto por 23 atletas.

\section{INSTRUMENTO E PROCEDIMENTOS}

Foi utilizado o instrumento denominado "Situações de Stress no Handebol" (SSH), desenvolvido por de Rose Junior, Simões e Vasconcellos (1994). Esse questionário é composto por 16 itens que correspondem a fatos inerentes a uma partida de handebol. Cada item apresenta duas possibilidades de resposta: "sim", quando a situação proporciona estresse ao atleta; e "não", se o fato não estressa o avaliado. Tal instrumento se encontra referenciado e fundamentado na literatura brasileira (DE ROSE JUNIOR et al., 1994). Além do SSH, há uma pergunta aberta que permite ao atleta identificar outras situações de jogo que possam lhe causar estresse.

Através de contatos prévios com colaboradores (atletas e treinadores de handebol) oriundos das regiões Oeste do Paraná e Campinas-SP, foram abordados os objetivos e métodos de desenvolvimento do estudo. Todos os informantes consentiram em fazer parte do estudo.

\section{ANÁLISE DE DADOS}

Fez-se uso da estatística descritiva, com o cálculo da freqüência e percentual de respostas "sim" dadas a cada um dos itens do questionário. Foi utilizado o mesmo critério de de Rose Junior et al. (1994), que estipularam como relevantes as cinco situações de estresse que receberam os maiores índices de respostas afirmativas. Em relação à pergunta aberta, as demais situações de estresse encontradas foram agrupadas em categorias, utilizando-se como referencial as sete grandes fontes de exigências estressantes descritas em Brandão (2000), e apresentadas conforme as freqüências e percentagens de resposta.

\section{RESULTADOS E DISCUSSÃO}

A figura 01 apresenta as percentagens de respostas "sim" dadas pelos atletas dos grupos Oeste do Paraná e Campinas a cada um dos 16 itens fechados contidos no instrumento. 
Figura 01: Percentagens de repostas "sim" dadas pelos atletas dos grupos Oeste do Paraná e Campinas às situações causadoras de estresse em partidas de handebol.

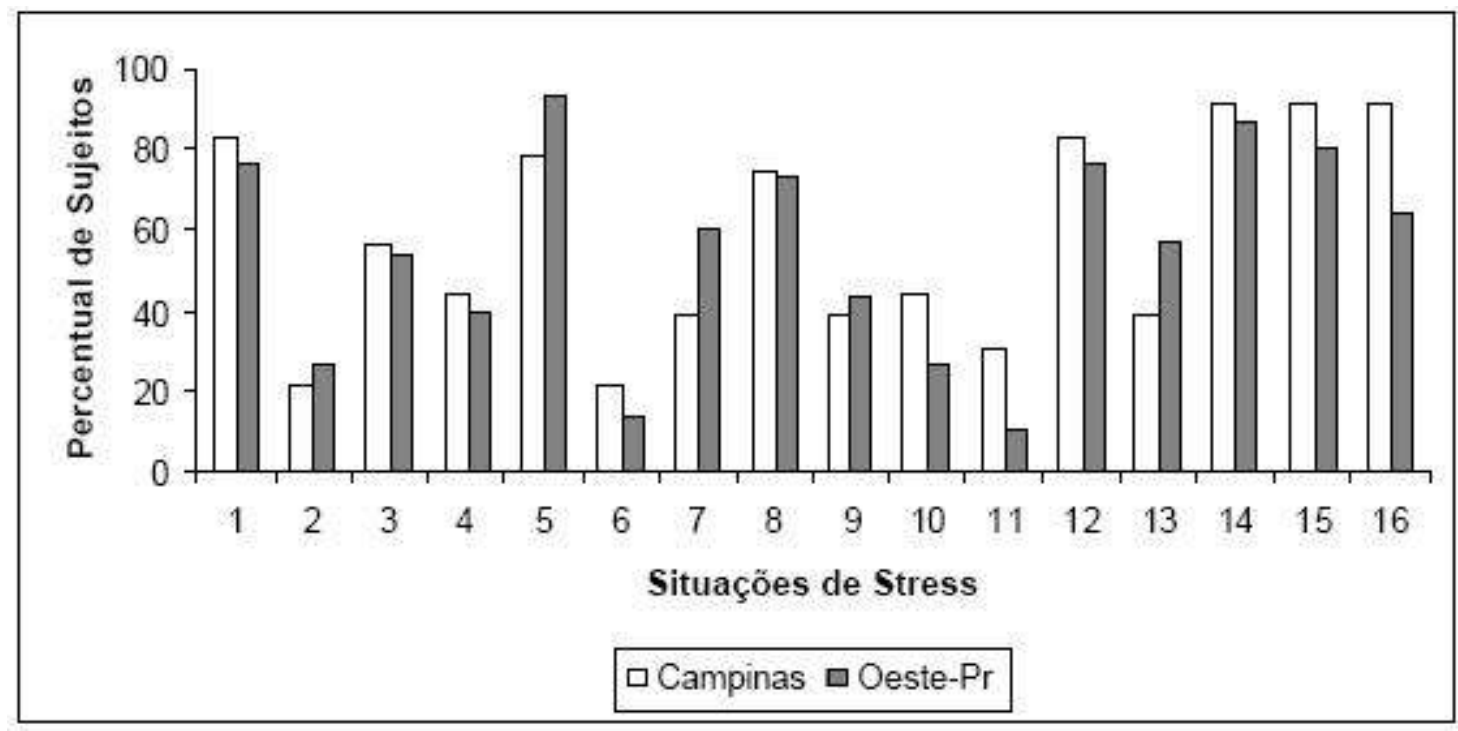

Para a melhor compreensão da figura, o quadro a seguir identifica os itens relativos aos números das situações de jogo causadoras de estresse.

Quadro 1- Itens referentes à numeração das situações de jogos causadoras de estresses em partidas de handebol

\begin{tabular}{|c|l}
\hline $\mathbf{N}^{\circ}$ & \multicolumn{1}{c}{ Item } \\
\hline 1 & Errar tiros de $7 \mathrm{~m}$ em momentos decisivos do jogo. \\
\hline 2 & Ser excluído por 2 min. muito cedo no jogo. \\
\hline 3 & Jogar em más condiços físicas. \\
\hline 4 & O adversário passa pelo meu lado mais forte. \\
\hline 5 & Estar perdendo para equipe tecnicamente inferior. \\
\hline 6 & Não começar jogando. \\
\hline 7 & Momentos decisivos de um jogo equilibrado. \\
\hline 8 & Estar perdendo por pouca diferença e o adversário está amarrando o jogo. \\
\hline 9 & Ser substituido por estar jogando mal. \\
\hline 10 & Ser perturbado pela minha torcida. \\
\hline 11 & Ser advertido pelo técnico na frente de todos. \\
\hline 12 & Errar um arremesso completamente livre. \\
\hline 13 & Estar sendo fortemente marcado e ficar isolado. \\
\hline 14 & Arbitragem estar prejudicando minha equipe. \\
\hline 15 & Ser excluido nos momentos decisivos da partida. \\
\hline 16 & Sofrer um gol devido a uma falha defensiva. \\
\hline
\end{tabular}


A partir das observações da figura 1 e do quadro 1, os cinco principais fatores apontados pelos integrantes do grupo Oeste do Paraná como geradores de estresse são, em ordem decrescente de percentagem, os seguintes: estar perdendo para equipe tecnicamente inferior (93,33\%); arbitragem estar prejudicando minha equipe (86,67\%); ser excluído nos momentos decisivos da partida (80\%); errar tiros de $7 \mathrm{~m}$ em momentos decisivos do jogo; e errar um arremesso completamente livre, sendo que as duas últimas ocasiões mencionadas empataram com $76,67 \%$ de consideração.

Quanto à identificação das demandas estressantes em handebolistas pertencentes ao grupo Campinas-SP, aparecem a seguir os cinco principais itens, seguidos de suas respectivas percentagens: arbitragem estar prejudicando minha equipe (91,30\%); ser excluído nos momentos decisivos da partida (91,30\%); sofrer um gol devido a uma falha defensiva (91,30\%); errar tiros de $7 \mathrm{~m}$ em momentos decisivos do jogo (82,61\%); e errar um arremesso completamente livre $(82,61 \%)$.

Ao se comparar os dados obtidos, percebeu-se que, dos cinco principais itens considerados estressantes por cada um dos grupos, quatro foram comuns a ambos: arbitragem estar prejudicando minha equipe; ser excluído nos momentos decisivos da partida; errar tiros de $7 \mathrm{~m}$ em momentos decisivos do jogo; e errar um arremesso completamente livre. A seguir, as quatro situações serão comentadas individualmente.

Os problemas em relação à arbitragem constituem-se em fatores situacionais externos, ou seja, não podem ser controlados pelos integrantes da equipe. Entretanto, as reações dos esportistas frente às marcações da arbitragem apresentam possibilidades de melhor enfrentamento. Quando o jogador recebe com insatisfação e irritação determinada orientação vinda da arbitragem, seu estado emocional pode variar em um contínuo que vai desde o descontrole (distresse) até a acentuação da motivação para a vitória (eustresse). Geralmente, no entanto, os desdobramentos de discussões com oficiais são de ordem negativa para os handebolistas, originando interferências no desempenho dos mesmos em quadra. Faz-se importante ressaltar que o árbitro esportivo ainda é uma figura pouco reconhecida e não profissionalizada (BRITO, 2001), a despeito da evolução do esporte moderno. Essa realidade dificulta a construção de uma relação harmônica do mesmo com os atletas de diversas modalidades.

Outra ocasião da partida julgada como forte causadora de estresse é a exclusão do atleta nos momentos decisivos do jogo. Apesar da coletividade da modalidade, o arremesso ao gol se configura como um fundamento individual que pode decidir o placar final da partida. Sendo assim, o jogador de 
handebol tende a buscar sua auto-superação durante os últimos instantes. Ao sofrer a exclusão, no entanto, o mesmo sente-se impotente por não tomar parte nas ações de seu time. A punição é resultado direto da tomada de decisão de um atleta. De acordo com Gréhaigne, Godbout e Bouthier (2001), o estresse se configura em dos fatores que, ao se inter-relacionarem, influenciam na tomada de decisão. Portanto, pode ocorrer uma inversão na relação causa-efeito ao longo de uma partida de handebol, sendo o estresse uma das causas da suspensão do atleta.

O tiro de 7 metros, no handebol, equivale-se à cobrança de pênalti no futebol. Essas circunstâncias representam grandes possibilidades de acerto ao atleta que as executam. Entretanto, a falha em atingir o objetivo desejado (no caso, o gol) promove uma pressão psicológica no jogador. Como os tiros de 7 metros são freqüentes no decorrer do jogo, aqueles que acontecem nos momentos finais têm conotação de elementos vitais na definição do resultado. Daí surge a demanda estressante ao indivíduo incumbido de realizar o arremesso. Corroborando com esse panorama, de Rose Junior (2002), ao investigar cerca de 500 atletas com idades entre 15 e 19 anos, praticantes das modalidades natação, tên ${ }^{i}$, basquetebol e futebol, observou que o fato de cometer erros em momentos decisivos se configurava como uma das situações competitivas que causava maiores índices de estresse nos participantes da pesquisa.

Ainda a respeito do arremesso, o erro desse fundamento por parte de um atleta completamente livre, ou seja, sem marcação, aponta para conseqüentes percepções de estresse. Devido à individualidade do fundamento, a responsabilidade da marcação do gol cabe inteiramente ao arremessador. Para Zamberlan (1999a), um dos fatores indispensáveis ao êxito no arremesso é o alto grau de concentração e decisão do atleta. Por isso, ao errar essa ação, o atleta se sente frustrado e culpado. Entretanto, tal falha pode servir de estímulo para aumentar seu foco na partida, bem como na correta execução técnica dos movimentos.

As percepções acerca das situações de jogo geradoras de estresse entre os dois grupos avaliados sugerem que não existem diferenças significativas entre ambos a respeito dos principais fatos estressantes dentro de uma partida de handebol. Porém, em termos gerais de sentimentos de demandas exaustivas, é possível notar que os handebolistas de Campinas tenderam a considerar as mesmas ocasiões como mais estressantes em comparação com seus pares da região Oeste do Paraná. Isso pôde ser interpretado pelos maiores escores de percentagens apresentados pelos integrantes do grupo Campinas em 11 dos 16 itens do questionário. 
Após a avaliação dos 16 itens, foram elencadas as respostas dadas à pergunta aberta, na qual os atletas poderiam relatar outras situações causadoras de estresse em uma partida de handebol que não estivessem presentes nos itens fechados do questionário. O quadro abaixo apresenta as situações estressantes relatadas, com suas freqüências e percentagens de respostas recebidas, para o grupo Oeste do Paraná. Visando a uma melhor compreensão, as respostas foram agrupadas e classificadas de acordo com as sete grandes fontes de exigências estressantes descritas em Brandão (2000).

Quadro 2 - Grandes fontes de exigências, situações de jogo causadoras de estresse em partidas de handebol, suas freqüências e percentagens de respostas recebidas referentes ao grupo Oeste do Paraná.

\begin{tabular}{|c|c|c|c|c|c|}
\hline Fonte de exigência & F & $\%$ & Situação estressante & F & $\%$ \\
\hline \multirow[t]{6}{*}{ Aspectos da competição } & \multirow[t]{6}{*}{09} & \multirow[t]{6}{*}{30,00} & Erros técuicos & $\overline{03}$ & 10,00 \\
\hline & & & Ser xingado(a) & 02 & 6,66 \\
\hline & & & Ser agredido(a) & 01 & 3,33 \\
\hline & & & $\begin{array}{l}\begin{array}{l}\text { Situaçôes referentes à } \\
\text { arbitragem }\end{array} \\
\end{array}$ & 01 & 3,33 \\
\hline & & & Ser cobrado(a) & 01 & 3,33 \\
\hline & & & Ataque bem marcado & 01 & 3,33 \\
\hline \multirow[t]{3}{*}{$\begin{array}{c}\text { Expectativas sobre o } \\
\text { desempenho }\end{array}$} & \multirow[t]{3}{*}{05} & \multirow[t]{3}{*}{16,66} & $\begin{array}{l}\text { Mau desempenho } \\
\text { individual ou coletivo }\end{array}$ & 02 & 6,66 \\
\hline & & & $\begin{array}{l}\text { A equipe ser melhor } \\
\text { tecnicamente que a equipe } \\
\text { adversána }\end{array}$ & 02 & 6,66 \\
\hline & & & $\begin{array}{l}\text { Falta de empenho da } \\
\text { equipe }\end{array}$ & 01 & 3,33 \\
\hline \multirow[t]{2}{*}{ Fatores pessoais } & \multirow[t]{2}{*}{02} & \multirow[t]{2}{*}{6,66} & Pressão psicológica & 01 & 3,33 \\
\hline & & & Falta de concentração & 01 & 3,33 \\
\hline \multirow[t]{2}{*}{ Variáveis episódicas } & \multirow[t]{2}{*}{02} & \multirow[t]{2}{*}{6,66} & Bola muito cheia & 01 & 3,33 \\
\hline & & & $\begin{array}{l}\text { Técrico tira uma boa } \\
\text { atleta para punir o time }\end{array}$ & 01 & 3,33 \\
\hline $\begin{array}{l}\text { Relacionamentos com } \\
\text { pessoas significativas }\end{array}$ & - & - & - & -. & -. \\
\hline Experiências & 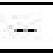 & 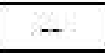 & - & 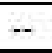 & 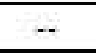 \\
\hline Demandas físicas & 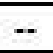 & -. & -- & .* & $\ddot{*}$ \\
\hline
\end{tabular}

$\mathrm{F}=$ Freqüência de respostas recebidas; $\%=$ Percentagem de respostas recebidas.

Os valores encontrados na análise referente ao grupo Campinas-SP estão descritos no quadro 3. 
Quadro 3: Grandes fontes de exigências, situações de jogo causadoras de estresse em partidas de handebol, suas freqüências e percentagens de respostas recebidas referentes ao grupo Campinas-SP.

\begin{tabular}{|c|c|c|c|c|c|}
\hline Fonte de exigência & $F$ & $\%$ & Situação estressante & $\mathrm{F}$ & $\%$ \\
\hline \multirow[t]{4}{*}{$\begin{array}{l}\text { Aspectos da } \\
\text { competição }\end{array}$} & \multirow[t]{4}{*}{06} & \multirow[t]{4}{*}{26,09} & $\begin{array}{l}\text { Soffer un gol ao final de } \\
\text { um jogo empatado }\end{array}$ & 03 & 13,04 \\
\hline & & & Enos técuicos & 01 & 4,35 \\
\hline & & & Ser agredido(a) & 01 & 4,35 \\
\hline & & & Ser cobrado(a) & 01 & 4,35 \\
\hline \multirow{2}{*}{$\begin{array}{l}\text { Expectativas sobre o } \\
\text { desempenho }\end{array}$} & \multirow[t]{2}{*}{05} & \multirow[t]{2}{*}{21,74} & Falta de empenho da equipe & 03 & 13,04 \\
\hline & & & $\begin{array}{l}\text { Mau desempenho } \\
\text { individual ou coletivo }\end{array}$ & 02 & 8,69 \\
\hline \multirow[t]{3}{*}{ Fatores pessoais } & \multirow[t]{3}{*}{03} & \multirow[t]{3}{*}{13,04} & Nervosismo & 01 & 4,35 \\
\hline & & & Falta de experiência & 01 & 4,35 \\
\hline & & & $\begin{array}{l}\text { Incapacidade de reação } \\
\text { frente à cobranças do } \\
\text { técrico e colegas }\end{array}$ & 01 & 4,35 \\
\hline \multirow[t]{2}{*}{$\begin{array}{l}\text { Relacionamentos com } \\
\text { pessoas significativas }\end{array}$} & \multirow[t]{2}{*}{03} & \multirow[t]{2}{*}{13,04} & $\begin{array}{l}\text { Desentendimentos } \\
\text { colega }(\mathrm{s}) \text { de equipe }\end{array}$ & 02 & 8,69 \\
\hline & & & $\begin{array}{l}\text { Jogar com pessoas que não } \\
\text { respondem ao andamento } \\
\text { do jogo }\end{array}$ & 01 & 4,35 \\
\hline Vanáveis episódicas &.- & - & $\overline{-}$ & - & - \\
\hline $\begin{array}{l}\text { Experiências } \\
\text { traumáticas }\end{array}$ &.- & -- & - & -- & -. \\
\hline Demandas físicas &.- & - & 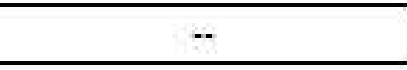 & $\cdots$ & $\ddot{*}$ \\
\hline
\end{tabular}

$\mathrm{F}=$ Freqüência de respostas recebidas; \% $=$ Percentagem de respostas recebidas.

Ao se comparar os resultados obtidos pelos dois grupos, foi possível perceber que os fatores inerentes à competição consistiram naqueles considerados como mais estressantes por ambos. Esse dado corroborou com o pressuposto de de Rose Junior (2002), segundo o qual a competição, em qualquer nível, apresenta quatro aspectos (confronto, demonstração, comparação e avaliação) que levam os indivíduos a constantes demandas psicofisiológicas.

As expectativas sobre o desempenho representaram a segunda grande fonte de exigências estressantes descrito pelos jovens handebolistas tanto do Oeste do Paraná quanto de Campinas. Essa constatação confirmou a ênfase na performance exigida pelo sistema esportivo atual aos desportistas pertencentes às 
categorias de base. De acordo com Brandão (2000), as expectativas são compostas por dois aspectos: metas e pressão. Em virtude das transformações biopsicossociais sofridas pelos indivíduos ao longo da adolescência, é provável que a "obrigação" de realizar boa performance e vencer não tenha sido bem assimilada por eles, abrindo espaço para o surgimento do estresse. Complementando essa perspectiva, Weinberg e Gould (2001) constataram a ocorrência de estresse em três situações do esporte infantojuvenil: derrota, importância do evento e tipo do esporte. No primeiro fator, o estresse é mais percebido nas derrotas do que nas vitórias. No segundo caso, as competições percebidas como mais importantes são aquelas nas quais seus participantes vivenciam mais estresse. Em relação ao tipo de esporte, as modalidades coletivas proporcionam menores índices de estresse aos seus praticantes quando comparadas às modalidades individuais.

Portanto, constatou-se que, mesmo quando lhes foi dada a possibilidade de mencionar uma situação geradora de estresse que não estivesse presente nos itens do questionário, esportistas de duas regiões geográficas diferentes do país, como Oeste do Paraná e Campinas, perceberam fontes de demandas de estresse semelhantes dentro de um jogo, que foram os próprios aspectos da competição e as expectativas sobre o desempenho.

\section{CONCLUSÕES}

O presente estudo teve como objetivos identificar as situações de jogo causadoras de estresse em atletas das categorias de base de handebol pertencentes a áreas geográficas e culturais distintas, nesse caso a parte Oeste do Estado do Paraná e o município de Campinas, no Estado de São Paulo, bem como comparar as percepções de estresse advindas dessas situações percebidas pelos esportistas das duas regiões. Concluiu-se que, entre os handebolistas do grupo Oeste do Paraná, o fato de estar perdendo para equipe tecnicamente inferior foi considerado como o agente estressor majoritário ao longo de uma partida, ao passo que os atletas de Campinas-SP julgaram três momentos da partida como maiores geradores de estresse: arbitragem estar prejudicando minha equipe; ser excluído nos momentos decisivos da partida; e sofrer um gol devido a uma falha defensiva.

Apesar da incompatibilidade apresentada pelos grupos quanto à percepção das principais situações causadoras de estresse, observou-se que, ao serem agrupadas as cinco situações com escores mais elevados em relação à sensação de estresse, quatro constituíram-se em ocasiões comuns aos dois grupos. Com isso, verificou-se que, a despeito dos cerca de 1.000 quilômetros de distância que separam o Oeste do Paraná de Campinas, bem como do fato dessas regiões terem recebido colonizações distintas, resultando em duas 
áreas com etnias e culturas diferentes, ocorreram semelhanças na percepção dos momentos em que os atletas de handebol sentiam-se mais estressados.

Sugere-se que, a partir desse estudo, novas abordagens cross-culturais possam ser desenvolvidas em estudos envolvendo a Psicologia do Esporte e o handebol. Sobre essas abordagens, Brandão (2007, p. 154) afirma que "... a forma de avaliar as situações esportivas e responder a elas nos treinamentos e competições se encontra sob influência de fatores culturais". Por se tratar de um país dotado de dimensões continentais, o Brasil apresenta inúmeros cenários culturais. Como exemplos de futuras investigações relevantes para a literatura, podem ser sugeridas comparações acerca de fatores psicológicos entre esportistas das regiões norte e sul, os extremos geográficos brasileiros.

\section{REFERÊNCIAS}

BRANDÃO, M. R. F. A Psicologia do exercício e do esporte e seus desafios para o milênio. In: BRANDÃO, M. R. F., MACHADO, A. A. (Org.). Coleção Psicologia do esporte e do exercício. São Paulo: Atheneu, 2007. v. 1, p. 143-157.

BRANDÃO, M. R. F. Fatores de stress em jogadores de futebol profissional. UNICAMP, 2000.

BRANDÃO, M. R. F.; CASAL, H. V.; GONZÁLEZ, E. Estrés en jugadores de fútbol: una comparación Brasil \& Colombia. Revista Digital Lecturas: Educación Física y Deportes, v. 7, n. 35, 2001.

BRITO, A. P. Psicologia do Desporto. Omniserviços: Lisboa, 2001. CONFEDERAÇÃO BRASILEIRA DE HANDEBOL (CBHb). Handbook 2002. 2002.

CONFEDERAÇÃO BRASILEIRA DE HANDEBOL (CBHb). Disponível em: $<$ http://www.brasilhandebol.com.br/>. Acesso em: 22 jan. 2007.

DE ROSE JUNIOR, D. A Competição como fonte de estresse no esporte. Revista Brasileira de Ciência e Movimento, 10 (4), 19-26,2002.

DE ROSE JUNIOR, D.; SIMÕES, A.; VASCONCELLOS, E. Situações de jogo causadoras de "stress" no handebol de alto nível. Revista Paulista de Educação Física, v. 8 n. 1, p. 30-37, 1994.

GRÉHAIGNE, J. F.; GODBOUT, P.; BOUTHIER, D. The teaching and learning of decision making in team sports. Quest, v. 53, n. 1, p. 59-76, 2001.

RAM, N.; STAREK, J.; JOHNSON, J. Race, ethnicity and sexual orientation: still a void in sport and exercise psychology? Journal of Sport and Exercise Psychology, v. 26, p. 250-268, 2004.

SAMULSKI, D. Psicologia do esporte. Barueri: Manole, 2002. 
WEINBERG, R. S.; GOULD, D. Fundamentos da psicologia do esporte e do exercício. Porto Alegre: Artmed, 2001.

ZAMBERLAN, E. Aprendizagem dos arremessos do handebol na escola do ensino fundamental e médio. Revista Treinamento Desportivo, v. 4, n. 1, p. 37-47, 1999a. . Handebol: escolar e de iniciação. Londrina: Treinamento Desportivo, 1999 b. 


\title{
Daniel Alvarez Pires
}

Universidade Federal do Amapá (UNIFAP)

\author{
Lucinar Jupir Forner Flores \\ Universidade Paranaense (UNIPAR)
}

\section{Maria Regina Ferreira Brandão \\ Universidade São Judas Tadeu (USJT)}

\section{Referência do artigo:}

\section{ABNT}

PIRES, D. A. et al. Situações de jogo causadoras de estresse em atletas das categorias de base de handebol: uma abordagem cross-cultural. Conexões, v. 6, p. 463-476, 2008.

\section{APA}

Pires, D. A., Flores, L. J. F., \& Brandão, M. R. F. (2008) Situações de jogo causadoras de estresse em atletas das categorias de base de handebol: uma abordagem cross-cultural. Conexões, 6, 463-476.

\section{VANCOUVER}

Pires DA, Flores LF, Brandão MRF. Situações de jogo causadoras de estresse em atletas das categorias de base de handebol: uma abordagem cross-cultural. Conexões, 2008; 6: 463-476. 